\title{
Pengaruh Temperatur Kalsinasi pada Sintesis Nanopartikel Silika Pantai Purus Kota Padang
}

\author{
Tika Yulian Rozi*, Astuti \\ Jurusan Fisika FMIPA Universitas Andalas, Padang \\ Kampus UNAND Limau Manih, Pauh Padang 25163 \\ *tikayulianrozi@gmail.com
}

\begin{abstract}
ABSTRAK
Sintesis nanopartikel silika telah berhasil dilakukan dengan menggunakan bahan pasir pantai Purus Sumatera Barat. Nanopartikel silika disintesis menggunakan metode kopresipitasi, yaitu dengan cara merendam pasir dengan $\mathrm{HCl} 10 \mathrm{M}$ selama 12 jam kemudian pasir direaksikan dengan $\mathrm{NaOH} 7 \mathrm{M}$. Larutan disaring kemudian dititrasi dengan $\mathrm{HCl} 10 \mathrm{M}$ sampai $\mathrm{pH}$ akhir mendekati 1-2. Hasil sintesis di dikalsinasi dengan variasi temperatur $600^{\circ} \mathrm{C}, 700^{\circ} \mathrm{C}$ dan $800^{\circ} \mathrm{C}$ selama 5 jam. Berdasarkan hasil XRD diketahui bahwa sampel yang dikalsinasi dengan temperatur $600{ }^{\circ} \mathrm{C}$ memiliki kristal silika kuarsa dengan hasil sampingan berupa $\mathrm{NaCl}$. Kristal silika kuarsa dan kristobalit ditemukan pada sampel dengan temperatur kalsinasi $700^{\circ} \mathrm{C}$ dan $800^{\circ} \mathrm{C}$. Ukuran kristal ketiga sampel lebih besar dari pada $100 \mathrm{~nm}$. Hasil SEM menunjukan bahwa semua sampel memiliki bentuk partikel yang tidak homogen dan mengalami penggumpalan.

Kata kunci : nanopartikel, silika, kalsinasi, XRD, SEM
\end{abstract}

\begin{abstract}
Synthesis of silica nanoparticles has been conducted from Purus coast sands of West Sumatra. The synthesis was conducted using coprecipitation method, by soaking the sands intolo M HCl for 12 hours and then were reacted with $7 \mathrm{M} \mathrm{NaOH}$. The solution was filtered and then titrated with $10 \mathrm{M} \mathrm{HCl}$ until $\mathrm{pH}$ of about 1-2. The synthesis result was calcined with temperature variation of $600{ }^{\circ} \mathrm{C}, 700{ }^{\circ} \mathrm{C}$ and $800^{\circ} \mathrm{C}$ for 5 hours. XRD patterns show that the sample which is calcined at a temperature of $600{ }^{\circ} \mathrm{C}$ has quartz silica crystal and $\mathrm{NaCl}$. Crystobalite and quartz silica crystal found in the samples with calcination temperature of $700{ }^{\circ} \mathrm{C}$ and $800^{\circ} \mathrm{C}$. Crystalline sizes of the three samples are larger than 100 nm. SEM result show that all samples have inhomogeus particle form and agglomerated.

Keywords: nanoparticles, silica, calcination, XRD, SEM.
\end{abstract}

\section{PENDAHULUAN}

Pasir pantai di Indonesia umumnya berwarna putih dan cenderung mengandung material berupa pasir kuarsa atau pasir silika. Pasir silika terdiri atas kristal-kristal silika (SiO2) dan mengandung senyawa pengotor seperti oksida besi, oksida kalsium, oksida alkali, oksida magnesium, tanah liat dan zat organik hasil sisa-sisa hewan serta tumbuhan (Fairus dkk., 2009)

Penggunaan pasir silika sudah berkembang meluas, baik langsung sebagai bahan baku utama maupun bahan campuran. Sebagai bahan baku utama, misalnya digunakan dalam industri gelas kaca, semen, mosaik keramik, bahan baku fero silikon, silicon carbide bahan abrasit (ampelas dan sand blasting), sedangkan sebagai bahan campuran, misal dalam industri cor, industri perminyakan dan pertambangan, bata tahan api (refraktori), dan lain sebagainya.

Pasir silika yang terdapat di alam dapat diubah ukurannya menjadi skala nanometer yang disebut dengan nanopartikel silika. Nanopartikel merupakan partikel yang memiliki ukuran <100 nm. Nanopartikel silika memiliki beberapa keunggulan yaitu luas permukaan terhadap volume lebih besar, ketahanan panas yang baik, kekuatan mekanik yang tinggi dan inert sehingga digunakan sebagai prekursor katalis, adsorben dan filter komposit (Kalapathy, dkk., 2000). Nanopartikel silika terdiri atas 2 yaitu amorf dan kristal. Nanopartikel silika amorf bisa digunakan dalam proses pembuatan substrat elektronik, substrat lapisan tipis, insulator listrik dan insulator termal. Nanopartikel silika kristal dapat dimanfaatkan sebagai katalis yang baik karena mempunyai luas permukaan yang besar, ketahanan panas yang baik, kekuatan mekanik yang tinggi dan inert. Partikel silika memiliki peran yang berbeda-beda untuk masingmasing produk yang dihasilkan, dimana kualitas produk ditentukan dari ukuran dan distribusi ukuran partikel silika itu sendiri di dalam sistemnya (Zawrah, dkk., 2009)

Nanopartikel silika dapat disintesis dengan beberapa motode, yaitu metode sol-gel, metode gas phase process, metode kopresipitasi dan lain-lain. Metode yang sering digunakan 
adalah metode kopresipitasi. Metode kopresipitasi merupakan salah satu metode sintesis senyawa anorganik yang didasarkan pada pengendapan lebih dari satu substansi secara bersamasama ketika melewati titik jenuhnya. Metode kopresipitasi mempunyai beberapa kelebihan diantaranya yaitu prosesnya yang menggunakan temperatur rendah dengan waktu yang dibutuhkan relatif lebih singkat dan juga merupakan metode yang sederhana dan mudah dilakukan. Beberapa zat yang paling umum digunakan sebagai zat pengendap dalam kopresipitasi adalah hidroksida, karbonat, sulfat dan oksalat (Rio, 2011). Proses kopresipitasi menggunakan alat dan bahan yang mudah diperoleh dengan biaya yang relatif murah (Jayanti, 2014).

Nanopartikel silika yang dihasilkan dari proses kopresipitasi dapat berupa amorf maupun kristal. Silika dalam struktur kristal memiliki susunan atom yang lebih teratur dari pada silika amorf. Nanopartikel silika dapat ditingkatkan kristalinitasnya dengan melakukan kalsinasi, yaitu pemanasan dengan suhu tinggi yang tidak melebihi titik lelehnya atau pengaruh tekanan (Nisa dan Munasir, 2015). Rizka dan Triwikantoro (2014) mensintesis nanopartikel silika dengan metode kopresipitasi menggunakan $\mathrm{HCl} 2 \mathrm{M}$ dan $\mathrm{NaOH} 7 \mathrm{M}$. Silika yang yang digunakan berasal dari pasir pantai Tuban, Jawa Timur yang dikalsinasi pada temperatur $900{ }^{\circ} \mathrm{C}$ dan $950{ }^{\circ} \mathrm{C}$ dengan waktu tahan $4,6,8$ dan 10 jam. Pada temperatur $900{ }^{\circ} \mathrm{C}$ selama kurang dari 8 jam masih berbentuk silika amorf, sedangkan pada kalsinasi $950{ }^{\circ} \mathrm{C}$ selama $4,6,8,10$ jam berbentuk gabungan dari silika amorf dan kristal, semakin lama waktu kalsinasi yang diberikan, puncak kristal dari fasa kristobalit semakin meningkat. Latif dkk (2014) dengan menggunakan metode dan sumber silika yang sama menghasilkan silika kuart pada temperatur $800^{\circ} \mathrm{C}$ dan $1000{ }^{\circ} \mathrm{C}$ sedangkan pada temperatur $1200{ }^{\circ} \mathrm{C}$ terbentuk silika kuart dan kristobalit dengan waktu tahan 4 jam.

Pada penelitian lain, Hayati dan Astuti (2015) telah mensintesis nanopartikel silika dari pasir pantai Purus kota Padang, dengan menggunakan metode kopresipitasi. Penelitian ini menggunakan $\mathrm{HCl} 10 \mathrm{M}$ dengan variasi terhadap konsentrasi $\mathrm{NaOH}$ yaitu $5 \mathrm{M}, 6 \mathrm{M}$ dan $7 \mathrm{M}$. Hasil sintesis $\mathrm{NaOH} 5 \mathrm{M}$ mempunyai fasa amorf, sedangkan fasa kristal ditemukan pada sampel dengan konsentrasi NaOH $6 \mathrm{M}$ dan 7 M, dengan ukuran kristal kecil dari $80 \mathrm{~nm}$. Penelitan tersebut tidak menggunakan kalsinansi. Penelitian ini dilanjutkan dengan melakukan kalsinasi dengan temperatur $600{ }^{\circ} \mathrm{C}, 700{ }^{\circ} \mathrm{C}$ dan $800{ }^{\circ} \mathrm{C}$ dan diharapkan menghasilkan nanopartikel silika dengan kristalinitas yang lebih tinggi.

\section{METODE}

Peralatan yang digunakan dalam penelitian ini adalah gelas ukur, pipet spatula logam, corong kaca, cawan keramik, lumpang, kertas saring, kertas ph, timbangan digital, oven, ayakan 200 mesh, furnace, los angeles machine dan hot magnetic stirrer. Sedangkan bahan yang digunakan adalah pasir pantai, aquades, $\mathrm{HCl} 10 \mathrm{M}$ dan $\mathrm{NaOH} 7 \mathrm{M}$.

Pengambilan sampel pasir dilakukan di pantai Purus Kota Padang. Awalnya pasir pantai di destruksi dengan cara penggerusan dengan Los Angeles machine dan pengayakan dengan ayakan 200 mesh, selanjutnya diekstraksi magnet dan kemudian disintesis dengan metode kopresipitasi.

Langkah-langkah metode kopresipitasi adalah sebagai berikut : sampel pasir direndam sebanyak $60 \mathrm{~g}$ dalam $\mathrm{HCl} 10 \mathrm{M}$ selama $12 \mathrm{jam}$. Perendaman ini bertujuan untuk melarutkan pengotor yang ada pada pasir sebelum dilanjutkan dengan sintesis. Kemudian sampel dicuci dengan aquades untuk memurnikannya kembali dan dikeringkan dengan oven. Selanjutnya direaksikan dengan $\mathrm{NaOH} 7 \mathrm{M}$, kemudian disaring dengan kertas saring. Larutan lolos saring dititrasi sedikit demi sedikit dengan $\mathrm{HCl}$ dengan mengontrol sampai $\mathrm{pH}$ akhir 1-2. Hasil titrasi dicuci dengan aquades untuk menghilangkan $\mathrm{NaCl}$ sampai lima kali dengan aquades $300 \mathrm{ml}$. Setelah itu dilakukan kalsinasi dengan variasi temperatur $600{ }^{\circ} \mathrm{C}, 700{ }^{\circ} \mathrm{C}$ dan $800{ }^{\circ} \mathrm{C}$ selama 5 jam. Setelah dikalsinasi dilakukan penggerusan dengan lumpang sehingga didapatkan serbuk silika.

Karakterisasi dilakukan dengan XRD (X-Ray Diffractometer) dan SEM (Scanning Electron Microscope) untuk mengetahui fasa kristalinitas sampel serta ukuran silika dan melihat morfologi permukaan silika yang dihasilkan. 


\section{HASIL DAN DISKUSI}

\subsection{Morfologi Permukaan Silikon Dioksida}

Morfologi permukaan sampel menggunakan SEM dapat dilihat pada Gambar 1. Pada sampel dengan temperatur kalsinasi $600{ }^{\circ} \mathrm{C}$ terlihat bahwa permukaan dari silika tidak homogen (tidak seragam), dimana terdapat beberapa aglomerasi (gumpalan). Bentuk partikel dan gumpalan yang dihasilkan tidak beraturan.

Hasil karakterisasi sampel pada temperatur kalsinasi $700{ }^{\circ} \mathrm{C}$ menghasilkan partikel dengan ukuran dan bentuk yang tidak beraturan. Sebagian besar dari partikel-partikel kecil tersebut membentuk partikel yang besar atau beraglomerasi dengan ukuran yang berbeda-beda. Hasil karakterisasi sampel pada temperatur $800{ }^{\circ} \mathrm{C}$ menggambarkan partikel dengan ukuran dan bentuk yang tidak beraturan terdiri dari beberapa gumpalan-gumpalan. Jadi, peningkatan temperatur kalsinasi menyebabkan perubahan struktur permukaan partikel silika yang dihasilkan. Semakin tinggi temperatur kalsinasi yang digunakan maka partikel yang dihasilkan semakin mengalami penggumpalan. Pada temperatur $700{ }^{\circ} \mathrm{C}$ struktur permukaan yang dihasilkan lebih homogen dari pada temperatur $600{ }^{\circ} \mathrm{C}$ dan $800{ }^{\circ} \mathrm{C}$.

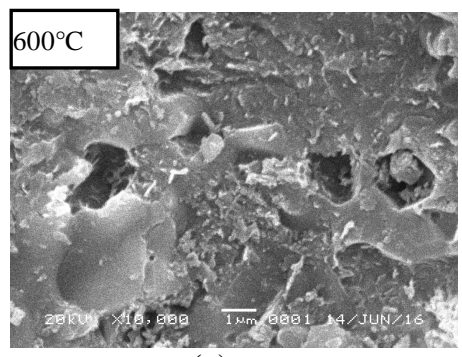

(a)

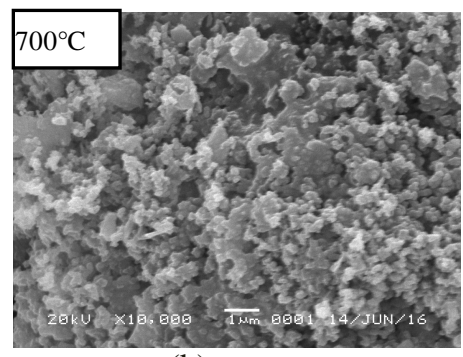

(b)

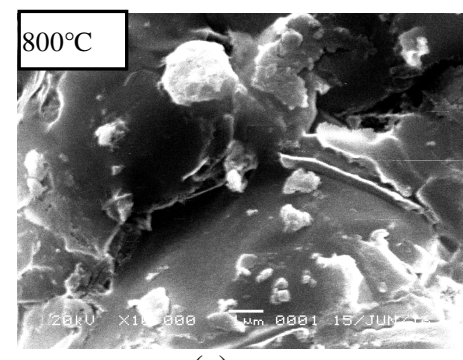

(c)

Gambar 1 Morfologi Permukaan Sampel Perbesaran 10.000x

\subsection{Hasil XRD Nanopartikel Silika}

Hasil XRD untuk temperatur kalsinasi $600{ }^{\circ} \mathrm{C}$ dapat dilihat pada Gambar 2. Pada Gambar 2 terlihat adanya puncak-puncak difraksi yang tajam. Puncak-puncak tersebut terdiri atas puncak difraksi silika kuart dan $\mathrm{NaCl}$. $\mathrm{NaCl}$ merupakan hasil sampingan dari sampel $\mathrm{A}$. Puncak-puncak difraksi yang tajam menunjukan bahwa struktur silika yang terbentuk adalah kristal. Kristal silika yang dihasilkan memiliki indeks miller [101] pada puncak tertinggi yaitu pada sudut $2 \theta=26,641^{\circ}$.

Pola-pola difraksi yang terbentuk merupakan akibat adanya hamburan atom-atom yang terletak pada bidang hkl dalam kristal tersebut. Menurut data ICDD dengan kode referensi 01079-1906 struktur kristal yang terbentuk adalah heksagonal dengan $\alpha=\beta=90^{\circ}$ dan $\gamma=120^{\circ}$. Hasil ini sesuai dengan teori dimana silika murni memiliki struktur heksagonal. Silika kuart yang dihasilkan memiliki nilai FWHM sebesar 0,1535.

Hasil XRD silika pada temperatur $700{ }^{\circ} \mathrm{C}$ dapat dilihat pada Gambar 3. Pada Gambar 3 terlihat adanya puncak-puncak difraksi yang tajam terdiri atas silika kuart dan silika kristobalit. Indeks miller [011] dihasilkan pada puncak tertinggi dengan sudut $2 \theta=26,631^{\circ}$ untuk silika kuart. Menurut data ICDD dengan kode referensi 01-086-1560 struktur kristal silika kuart yang terbentuk adalah heksagonal dengan $\alpha=\beta=90^{\circ}$ dan $\gamma=120^{\circ}$. Silika yang dihasilkan memiliki struktur heksagonal dengan nilai FWHM sebesar 0,1279.

Silika kristobalit yang dihasilkan berbentuk tetragonal dengan indeks miller [101] pada sudut $2 \theta=21,923$. Menurut data ICDD dengan kode 01-074-9378, silika kristobalit yang dihasilkan memiliki $\alpha=\beta=\gamma=90^{\circ}$ dengan nilai FWHM sebesar 0,1023.

Gambar 4 merupakan hasil XRD silika dengan temperatur kalsinasi $800{ }^{\circ} \mathrm{C}$. Pada gambar 4 terlihat struktur silika yang terbentuk merupakan kristal dimana terdapat banyak puncak-puncak difraksi. Menurut data ICDD dengan kode referensi 01-075-8320, struktur kristal silika kuart yang terbentuk adalah heksagonal. Puncak tertinggi pada sudut $2 \theta=26,600^{\circ}$ dan nilai FWHM sebesar 0,1279. 
Selain menghasilkan silika kuart, sampel C juga menghasilkan silika kristobalit. Silika kristobalit yang terbentuk berstruktur tetragonal dengan indeks miller [101] pada sudut $2 \theta=$ 21,923. Menurut data ICDD dengan kode 01-074-9378, silika kristobalit yang dihasilkan memiliki $\alpha=\beta=\gamma=90^{\circ}$ dengan nilai FWHM sebesar 0,1535 .

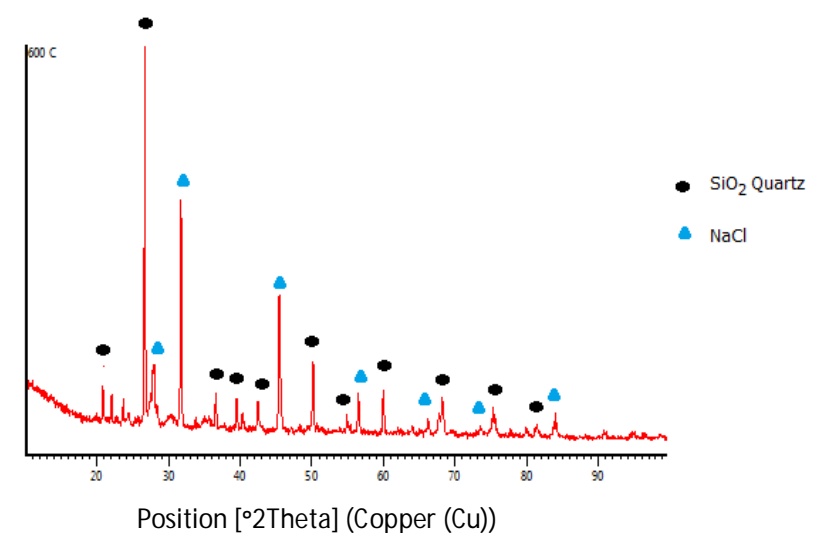

Gambar 2 Hasil XRD Silika dengan Temperatur Kalsinasi $600{ }^{\circ} \mathrm{C}$

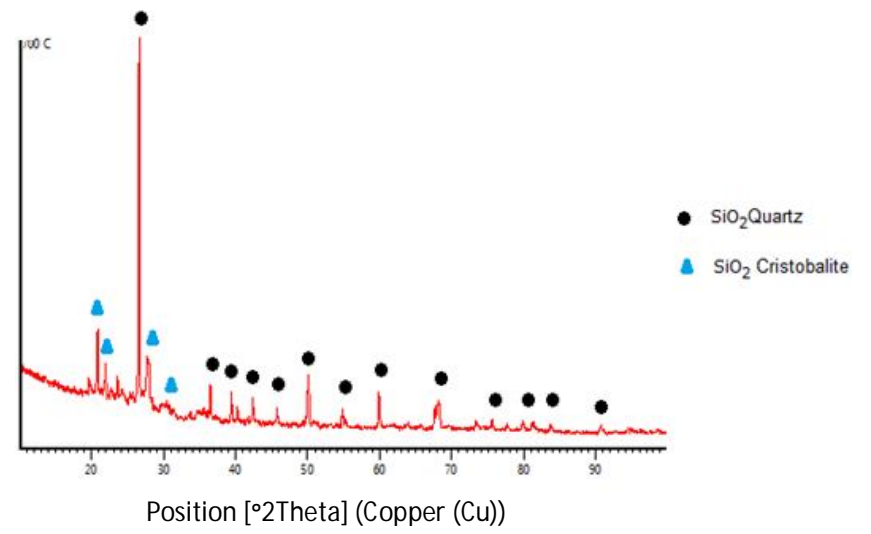

Gambar 3 Hasil XRD Silika dengan Temperatur Kalsinasi $700{ }^{\circ} \mathrm{C}$

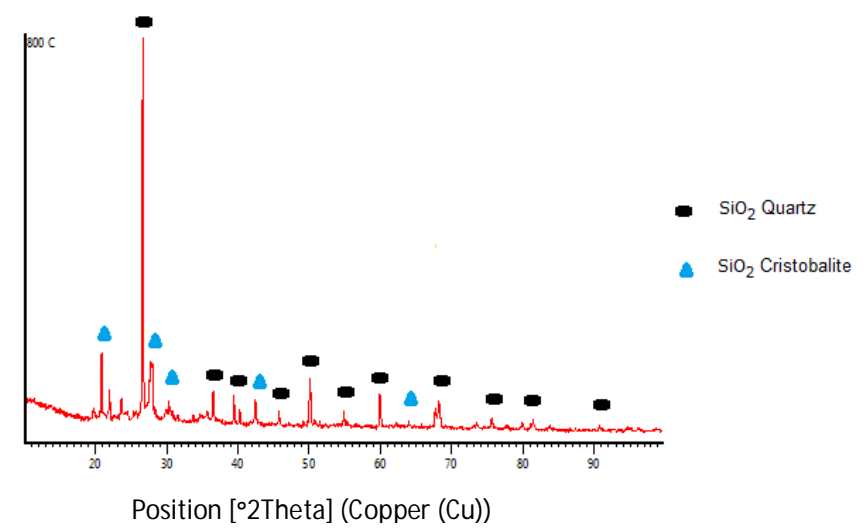

Gambar 4 Hasil XRD Silika dengan Temperatur Kalsinasi $800{ }^{\circ} \mathrm{C}$

Sampel C mempunyai tingkat kristalinitas yang lebih tinggi dibandingkan sampel B. Perbedaan temperatur menyebabkan perubahan struktur kristal. Struktur kristal mengalami perubahan karena posisi atom-atom dapat berubah seiring dengan kenaikan temperatur. Struktur atom yang terbentuk semakin kuat sehingga kristalinitas silika yang dihasilkan semakin meningkat. Hal ini sesuai dengan teori, semaki tinggi temperatur kalsinasi yang digunakan maka kristalinitas nanopartikel silika yang dihasilkan akan semakin tinggi. 
Pola difraksi XRD juga dapat menentukan ukuran kristal. Ukuran kristal dihitung dengan menggunakan persamaan Scherrer. Hasil perhitungan ukuran kristal dari silika dengan variasi temperatur kalsinasi $600{ }^{\circ} \mathrm{C}, 700{ }^{\circ} \mathrm{C}$ dan $800{ }^{\circ} \mathrm{C}$ dapat dilihat pada Tabel 1.

Tabel 1 Ukuran kristal Silika dengan variasi temperatur kalsinasi

\begin{tabular}{ccccc}
\hline Sampel & $\begin{array}{c}\text { Temperatur } \\
\text { kalsinasi }\left({ }^{\circ} \mathbf{C}\right)\end{array}$ & $\boldsymbol{B}(\mathbf{r a d})$ & $\boldsymbol{\theta}\left({ }^{\circ}\right)$ & $\boldsymbol{D}(\mathbf{n m})$ \\
\hline $\mathrm{A}$ & 600 & 0,00133886 & 13,32725 & 106,370 \\
$\mathrm{~B}$ & 700 & 0,00111560 & 13,29695 & 127,624 \\
$\mathrm{C}$ & 800 & 0,00111560 & 13,30175 & 127,670 \\
\hline
\end{tabular}

Tabel 1 menjelaskan bahwa peningkatan temperatur dari $600{ }^{\circ} \mathrm{C}$ menjadi $700{ }^{\circ} \mathrm{C}$ memberikan perubahan ukuran kristal yang cukup tinggi. Perubahan ini disebabkan karena nilai FWHM yang dihasilkan sangat jauh berbeda. Selain itu, temperatur $600{ }^{\circ} \mathrm{C}$ merupakan temperatur yang tidak jauh berbeda dengan temperatur kuart rendah. Ukuran kristal sampel B dengan sampel $\mathrm{C}$ tidak jauh berbeda karena temperatur kedua sampel masih berada pada rentang silika kuart tinggi. Pada kuart tinggi perubahan kristal yang dihasilkan tidak terlalu signifikan.

Tabel 2 Volume unit sel dengan variasi temperatur kalsinasi

\begin{tabular}{clcccc}
\hline Sampel & $\begin{array}{c}\text { Struktur } \\
\text { Silika }\end{array}$ & $\boldsymbol{a}\left(\mathbf{c}^{\prime}\right)$ & $\left.\boldsymbol{b} \mathbf{(}^{\prime}\right)$ & $\boldsymbol{c}\left(^{\prime}\right)$ & $\begin{array}{c}\text { Volume } \\
\text { Unit Sel }\end{array}$ \\
\hline $\mathrm{A}$ & Kuart & 4,9134 & 4,9134 & 5,4052 & 130,49 \\
\hline \multirow{2}{*}{$\mathrm{B}$} & Kuart & 4,9160 & 4,9160 & 5,4054 & 130,63 \\
& Kristobalit & 4,9836 & 4,9836 & 4,9836 & 123,77 \\
\hline \multirow{2}{*}{$\mathrm{C}$} & Kuart & 4,9230 & 4,9230 & 5,4090 & 131,09 \\
& Kristobalit & 4,9836 & 4,9836 & 6,9549 & 172,73 \\
\hline
\end{tabular}

Tabel 2 memperlihatkan karakteristik nanopartikel silika serta volume unit sel yang dihasilkan. Pada sampel A hanya terbentuk silika kuart sedangkan sampel B dan C sudah ditemukan silika dengan tingkat kristalinitas yang lebih tinggi yaitu silika kristobalit. Selain itu, dengan peningkatan temperatur juga terjadi peningkatan pada volume unit sel silika yang dihasilkan.

Struktur silika kuart yang dihasilkan oleh ketiga sampel memiliki volume unit sel yang tidak jauh berbeda. Perbedaan yang tidak terlalu jauh disebabkan karena temperatur yang digunakan tergolong pada temperatur silika kuart tinggi. Namun demikian, silika kristobalit yang dihasilkan oleh sampel $\mathrm{B}$ dan sampel $\mathrm{C}$ memiliki perbedaan volume unit sel dengan rentang yang cukup jauh. Perubahan temperatur mempengaruhi posisi atom- atom silika, sehingga terjadi perbedaan volume unit sel pada temperatur yang berbeda.

\section{KESIMPULAN}

Hasil SEM menunjukan bahwa semakin tinggi temperatur kalsinasi yang digunakan menyebabkan partikel silika semakin menggumpal. Pada temperatur $600{ }^{\circ} \mathrm{C}$ dan $700{ }^{\circ} \mathrm{C}$ masih terlihat adanya partikel-partikel yang tidak mengalami penggumpalan. Namun pada temperatur $800{ }^{\circ} \mathrm{C}$ tidak terlihat adanya partikel-partikel yang tidak menggumpal.

Hasil XRD nanopartikel silika dari pasir pantai Purus Kota Padang pada temperatur kalsinasi $600{ }^{\circ} \mathrm{C}$ menghasilkan silika kuart dengan struktur heksagonal. Sampel tersebut menghasilkan $\mathrm{NaCl}$ sebagai hasil sampingan. Sedangkan penggunaan temperatur kalsinasi 700 ${ }^{\circ} \mathrm{C}$ dan $800{ }^{\circ} \mathrm{C}$ menghasilkan silika kuart dan silika kristalobalit. Silika kuart yang dihasilkan berstruktur heksagonal. Struktur tetragonal dihasilkan oleh silika kristalobalit. Ukuran kristal silika pada temperatur $600{ }^{\circ} \mathrm{C}$ sebesar $106,370 \mathrm{~nm}$, pada temperatur $700{ }^{\circ} \mathrm{C}$ sebesar 127,624 dan pada temperatur $800^{\circ} \mathrm{C}$ sebesar 127,670 . 


\section{DAFTAR PUSTAKA}

Fairus, Sirin., Haryono., Sugita, H., M., Sudrajat, Agus, 2009, Proses Pembuatan Waterglass dari Pasir Silika dengan Pelebur Natrium Hidroksida, Jurnal Teknik Kimia Indonesia, Vol. 8, No. 2, hal. 56-62.

Hayati, R., Astuti, 2015, Sintesis Nanopartikel Silika dari Pasir Pantai Purus Padang Sumatera Barat Dengan Metode Kopresipitasi, Jurnal Fisika Unand, Vol. 4, No. 3, Fisika UNAND, hal. 282-287.

Jayanti, D.N., 2014, Optimalisasi Parameter pH pada Sintesis Nanosilika dari Pasir Besi Merapi Dengan Ekstraksi Magnet Permanen Menggunakan Metode Kopresipitasi, Skripsi, Fisika, UIN Sunan Kalijaga, Yogyakarta.

Kalapathy., Proctor, A., Shultz, J., 2000, A Simple Method For Production of Pure Silica From Rice Hull Ash, Bioresource Technology, Vol. 73, hal. 257-262.

Latif, C, Triwikantoro, Munasir, 2014, Pengaruh Variasi Temperatur Kalsinasi pada Struktur Silika. Jurnal Sains dan Seni Pomits, Vol. 3, No.2.

Nisa, Z dan Munasir, 2015, Studi Morfologi Silika Hasil Kalsinasi dengan Metode Sintesis Hydrotermal - Kopresipitasi, Jurnal Fisika, Vol. 4,No. 1,hal. 41-44.

Rio, B.F., 2011, Sintesis Nanopartikel SiO2 Menggunakan Metode Sol-Gel dan Aplikasinya Terhadap Aktifitas Sitotoksik, Jurnal Nanoteknologi, UNAND, Padang.

Rizka, A. B dan Triwikantoro, 2014, Pengaruh Temperatur Kalsinasi dan Waktu Penahanan terhadap Pertumbuhan Kristal Nanosilika, Jurnal Teknik Pomits, Vol. 1, No. 1, ITS, hal. $1-5$.

Zawrah, M.F., EL-Kheshen, 2009, Facile And Economic Synthesis of Silica Nanoparticles, Journal of Ovonic Research, Vol. 5, hal 129-133. 